\title{
Epidemiology of community-acquired pneumonia in Edmonton, Alberta: An emergency department-based study
}

\author{
Thomas J Marrie MD, Jane Q Huang MApplSc
}

\begin{abstract}
TJ Marrie, JQ Huang. Epidemiology of community-acquired pneumonia in Edmonton, Alberta: An emergency departmentbased study. Can Respir J 2005;12(3):139-142.

Patients aged 17 years and older who presented to seven emergency departments in Edmonton, Alberta over a two-year period with community-acquired pneumonia $(n=8144)$ were studied. The admission rates were 271/100,00 and 296/100,000 persons for year 1 and year 2 of the study, respectively. The admission rate increased with increasing age, peaking at 4639/100,000/year for those 90 years of age and older. In contrast, the percentage of patients who were admitted to an intensive care unit was highest for those in the younger age groups between 17 and 59 years of age. From 59 years of age and older, there was a progressive decline in the percentage of patients admitted to an intensive care unit, with approximately $1 \%$ of those in the 90 years and older age group admitted. A pronounced seasonal effect on the number of patients presenting to emergency department was also noted. During the winter months, there was up to a $50 \%$ increase in the number of cases compared with the summer months.
\end{abstract}

Key Words: Admission rate; Community-acquired pneumonia; Epidemiology

There have been several population-based studies of the inci1 dence of community-acquired pneumonia (CAP) (1-4). All of these studies have defined pneumonia on the basis of clinical features and the presence of an opacity on chest radiograph diagnosed as pneumonia by a radiologist (1-4). Population-based CAP studies are difficult to perform, and most studies have examined small populations. With changing health care demands, there has been increased emphasis on treating as many patients as possible on an ambulatory basis. This form of care is ideally delivered in a family physician's office. However, up to one-third of the population in the Edmonton, Alberta area does not have a family doctor and these individuals often use the emergency department for routine medical care (5). Physicians in the emergency department often read the chest radiographs and make a diagnosis of pneumonia before receiving a radiologist's interpretation. The objective of the current study was to define the epidemiology of CAP in an emergency department setting as diagnosed by emergency department physicians. A second objective was to determine the seasonal effect on the number of patients presenting to emergency facilities with pneumonia.

\section{METHODS}

Study sites

Edmonton, Alberta, is a city of 666,505 adults aged 17 years and older that is served by six hospitals and one freestanding emergency
Épidémiologie de la pneumonie extra-hospitalière à Edmonton en Alberta : Étude basée dans un service d'urgence

\begin{abstract}
Nous avons étudié les patients âgés de 17 ans et plus qui se sont présentés pour pneumonie extra-hospitalière dans sept services d'urgences d'Edmonton, en Alberta, au cours d'une période de deux ans $(\mathrm{n}=8144)$. Les taux d'hospitalisation ont été de 271/100 000 et de 296/100 000 personnes pour l'an 1 et l'an 2 de l'étude, respectivement. Le taux d'hospitalisation augmentait avec l'âge avec une pointe à 4 639/100 000 ans pour les patients de 90 ans et plus. Par contre, le pourcentage de patients hospitalisés aux soins intensifs a été plus élevé chez les sujets plus jeunes, soit de 17 à 59 ans. À partir de l'âge de 59 ans, on a noté un déclin progressif du pourcentage de patients hospitalisés aux soins intensifs, $1 \%$ environ des sujets de 90 ans et plus y ayant été admis. On a en outre noté un effet prononcé des saisons sur le nombre de patients qui ont consulté aux urgences. Au cours des mois d'hiver, une augmentation pouvant atteindre $50 \%$ du nombre de cas a été enregistrée comparativement aux mois d'été.
\end{abstract}

room. There are two tertiary care hospitals, two hospitals that provide secondary and some tertiary care, and two community hospitals.

\section{Study population and definition of CAP}

A pneumonia pathway consisting of components for managing pneumonia on an ambulatory basis and for managing pneumonia in patients requiring hospital admission was implemented November 15, 2000, and continued throughout the study at all hospitals and the one freestanding emergency department in Edmonton. Patients were enrolled into the pathway if they presented to the emergency department at one of the seven sites with two or more symptoms or signs of CAP, plus radiographic evidence of pneumonia as interpreted by the emergency room physician or internal medicine consultant. Symptoms and signs of CAP included cough (productive or nonproductive), pleuritic chest pain, shortness of breath, temperature higher than $38^{\circ} \mathrm{C}$ and crackles on auscultation. Patients were excluded from the pathway if they were thought to have aspiration pneumonia (year 1 only), tuberculosis, cystic fibrosis or if they required direct admission to the intensive care unit (ICU). Pregnant and nursing mothers and immunosuppressed patients (greater than $10 \mathrm{mg} /$ day of prednisone or other immunosuppressive drugs) were also excluded. Demographic, chest radiographic data and the reason for exclusion were collected on all patients who were not eligible for enrollment into the pathway. Patients from nursing homes were included as CAP. Patients who had been hospitalized within the previous two weeks were

Department of Medicine, University of Alberta, Edmonton, Alberta

Correspondence and reprints: Dr Thomas J Marrie, 2J2.01 Walter C Mackenzie Health Sciences Center, 8440112 Street, Edmonton, Alberta

T6G 2R7. Telephone 780-492-9728, fax 780-492-7303, e-mail tom.marrie@ualberta.ca 


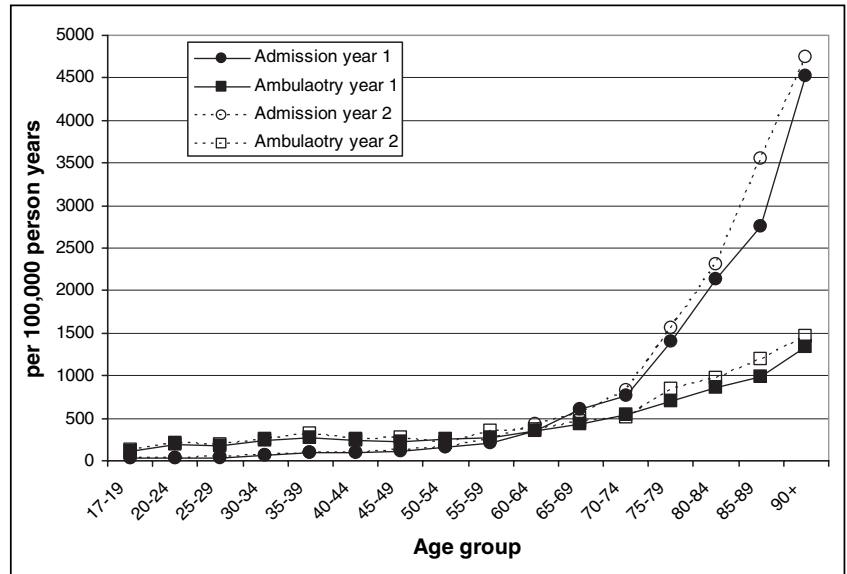

Figure 1) Admission rate and ambulatory pneumonia rate for patients who presented to an emergency department with pneumonia during years 1 and 2

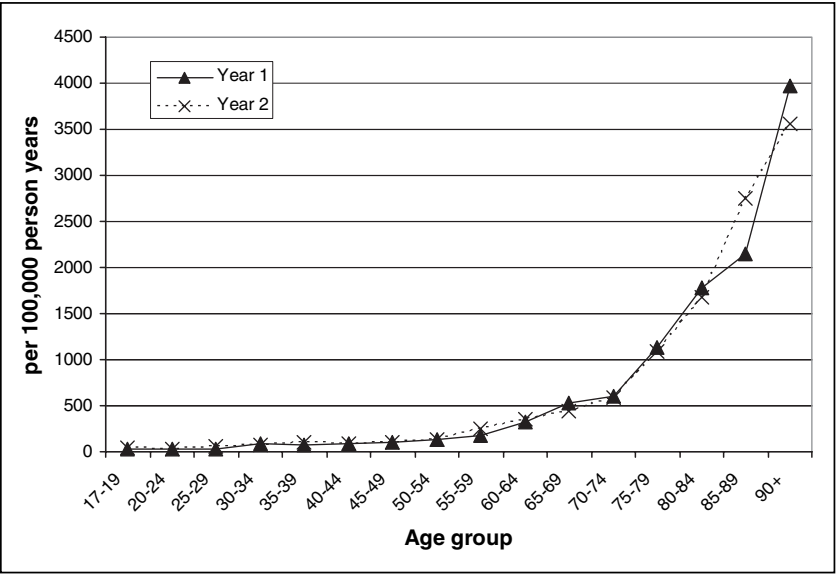

Figure 2) Total pneumonia (definite plus clinical) admission rate for women in years 1 and 2

thought to have nosocomial pneumonia and no data were collected on these patients. Visits to the emergency room for pneumonia within one month of the initial visit and re-admissions within two weeks of the initial admission were not included.

Six research nurses were hired to assist with the implementation of the pathway and perform data collection.

Populations for which rates were calculated were defined as follows:

- Definite pneumonia: all patients (both pathway and excluded; ambulatory and admitted) who met the clinical criteria and had a chest radiograph read by a radiologist as pneumonia.

- Clinical pneumonia: all patients who met the clinical criteria and had a chest radiograph read by an emergency department physician as pneumonia and by a radiologist as no pneumonia.

- Pneumonia requiring admission: all patients who were admitted including definite and clinical pneumonia.

- Pneumonia treated on an ambulatory basis: all patients who were discharged from emergency to be treated at home.

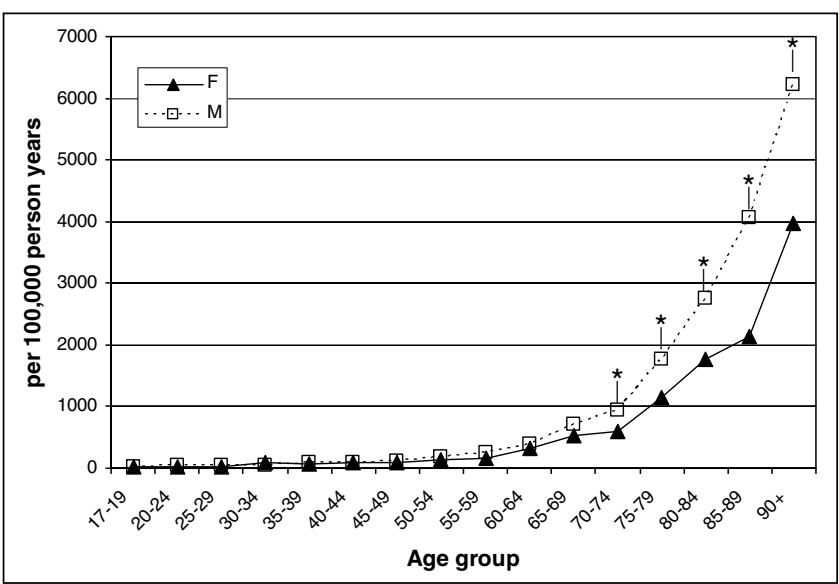

Figure 3) Total pneumonia admission rate for men and women in year 1. *Age groups for which the admission rate was higher for men than women. F Females; M Males

- Pneumonia requiring admission to an ICU: patients with definite plus clinical pneumonia who were admitted to an ICU.

\section{Statistical analysis}

The rate of admission for men was compared with that of women using the $\chi^{2}$ test.

The seasons were defined using the calendar definition, although cold weather (winter) starts in Edmonton in November and ends in early April.

The Research Ethics Committee at the University of Alberta in Edmonton, Alberta, approved the study.

\section{RESULTS}

During the two years of the study, a total of 8144 patients had a diagnosis of pneumonia made in the seven emergency departments. Ninety-five per cent (7737 patients) were managed according to the pneumonia pathway. Five per cent (407 patients) did not qualify for the pathway.

Fifty-two percent $(n=4259)$ of patients were treated on an ambulatory basis and $42.7 \%(n=3478)$ were admitted to hospital. Four hundred seven ( $5 \%$ ) of the patients who were admitted to hospital were admitted to an ICU.

The overall admission rate per 100,000 adults for pneumonia was very similar for years 1 and 2 of the study at 271 and 296 , respectively. The rate for ambulatory pneumonia was similar for the two years at $289 / 100,000$ and $315 / 100,000$ persons, respectively. The age-specific admission rate was quite low up to 49 years of age; however, there were major increases in the admission rate every five years thereafter, peaking at 4639 admissions $/ 100,000$ persons in the 90 years and older age group. Figure 1 shows the age-specific admission rate in fiveyear intervals. Figure 1 also shows the rate of ambulatory pneumonia by five-year age group. In Figure 2, the admission rates are shown for women for both years of the study. Of note, there was very little difference in the admission rates by study year. Figure 3 shows the admission rates for men and women for year 1 . From 70 years of age and older, the admission rates for pneumonia were significantly higher for men $(\mathrm{P}<0.01)$. In year 1 , the rates were higher for pneumonia among women 30 to 34 years of age, while there was no difference among the other age groups (Figure 3 ). In year 2, there was no difference 


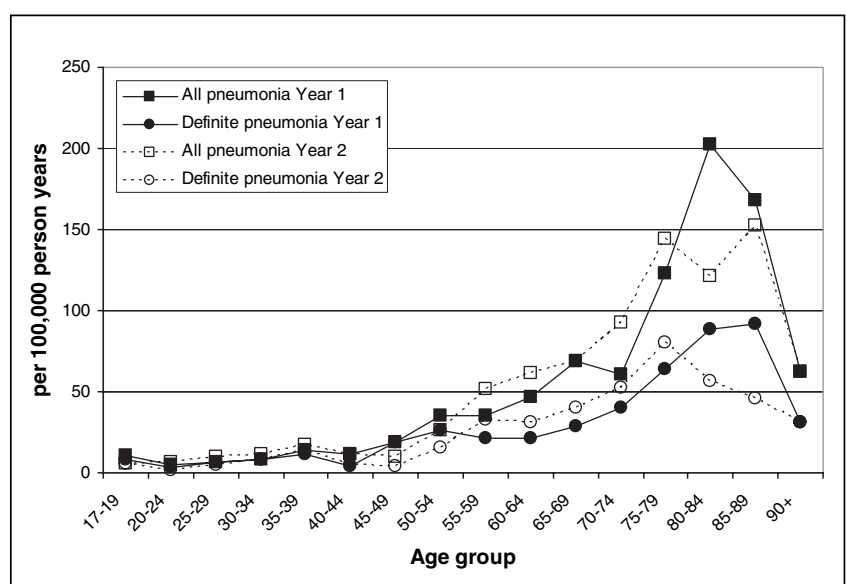

Figure 4) Intensive care unit admission rate for patients with pneumonia (definite plus clinical pneumonia), and definite pneumonia in years 1 and 2

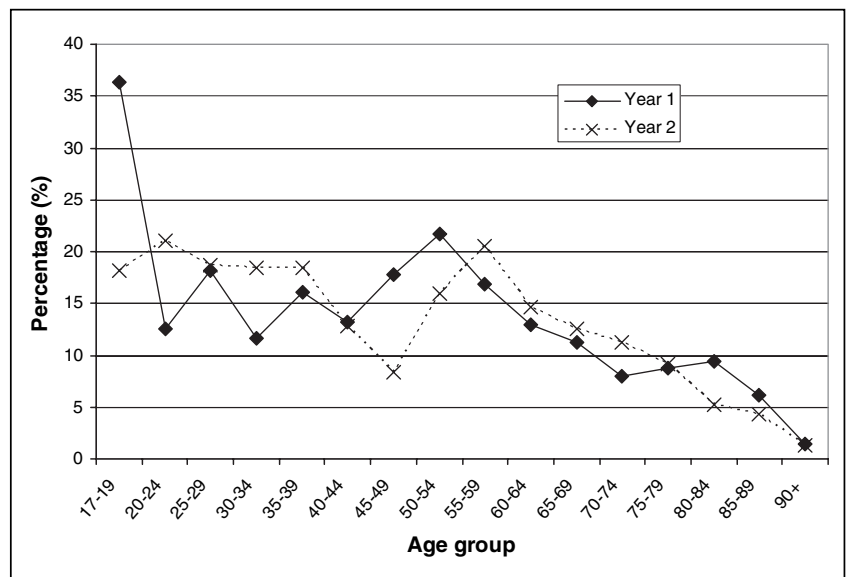

Figure 5) Percentage of patients with pneumonia who required admission to hospital and were admitted to an intensive care unit in years 1 and 2

in the admission rate for men and women in the younger age groups, while men were admitted at a higher rate at 50 to 54 years of age and 60 years of age and older (data not shown).

Figure 4 shows the admission rates per 100,000 persons/year with pneumonia (all cases) and definite pneumonia to an ICU. The rate peaked for those patients who were 80 to 84 years of age, at 202 cases/100,000 persons/year in year 1 .

Figure 5 shows the percentage of patients with pneumonia admitted to an ICU by age group. The highest percentage of patients admitted to the ICU was in the younger age groups, from 17 to 59 years of age. For those 59 years of age and older, there was a progressive decline in the per cent of patients admitted to the ICU with pneumonia, with approximately $1.4 \%$ of patients 90 years of age and older being admitted to an ICU.

Figure 6 shows the percentage of patients who were admitted according to age group. Up to 49 years of age, $32 \%$ of all patients who presented to the emergency departments and were diagnosed with pneumonia were admitted. For those patients 49 years of age and older, the percentage of patients who were admitted continued to increase, peaking at $76 \%$ to $77 \%$ for those who were 90 years of age and older.

The seasonal effect on the number of patients with pneumonia presenting to emergency departments is shown in Figure 7. Of note, the number of patients presenting to the

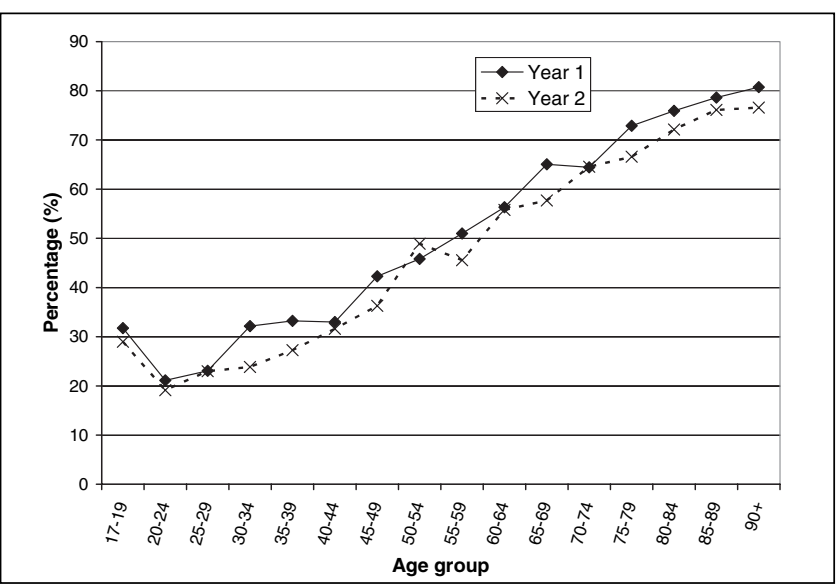

Figure 6) Percentage of patients by age group who presented to an emergency department with pneumonia and were admitted to hospital

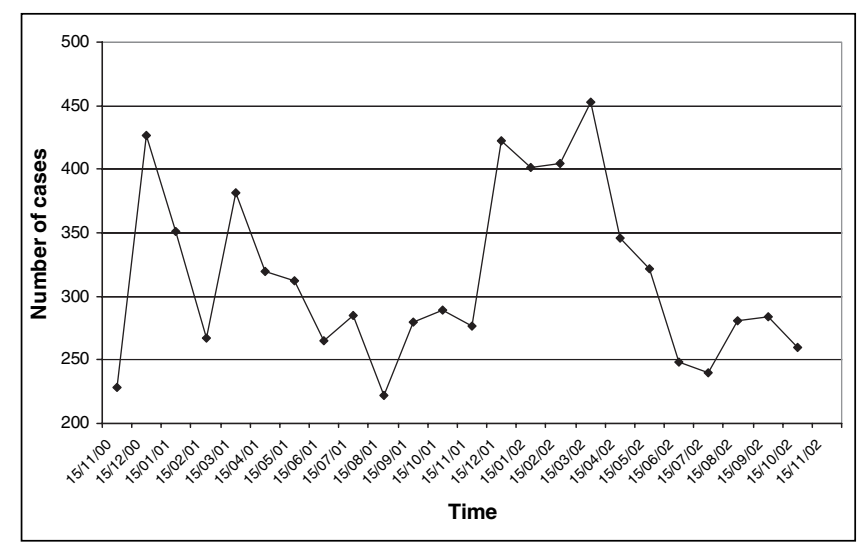

Figure 7) Number of persons with pneumonia by month from November 15, 2000, to November 14, 2002

emergency department in the winter months was almost twice as many as those who did so in the summer months

\section{DISCUSSION}

This is the first comprehensive study examining the rate of pneumonia presenting to emergency departments in a large Canadian city. A unique feature of our study is the inclusion of all patients with a clinical diagnosis of pneumonia. In a separate study that examined a subset of the current population of patients who were admitted to hospital, we found that patients without a radiographic diagnosis of pneumonia were older and had a higher severity of illness score than those who had a radiographic diagnosis of pneumonia (6). The rates of bacteremia, positive sputum culture and mortality were similar in the two populations (6).

In a population-based study carried out in Finland (2), the incidence of pneumonia was $11.6 / 1000$ persons/year. In the Finnish working population (ages 15 to 64 years), the mean annual hospitalization rate was $2.67 / 1000$ persons for men and $1.10 / 1000$ persons for women (3). The hospitalization rate for all adult men and women in Edmonton was $282 / 100,000$ persons/year and 261/100,000 persons/year, respectively, in the first year of the study, and 329/100,000 persons/year and 265/100,000 persons/year in the second year of the study. Almirall et al (4) studied all persons 14 years of 
age and older who were residents in the Maresme region in Barcelona, Spain. They excluded patients with nursing homeacquired pneumonia and aspiration pneumonia. The annual incidence of pneumonia in this study was 567 persons/ $100,000 /$ year; however, $48 \%$ of all patients with pneumonia required admission to hospital. A generally accepted figure is that $70 \%$ of patients with CAP are treated in the community and $30 \%$ are admitted to hospital (5). In the current study, $48 \%$ of the patients who presented to emergency departments were admitted to hospital. If we included all the patients who had a diagnosis of pneumonia made in their physicians' offices and walk-in clinics, the admission rate for pneumonia in Edmonton would likely be lower than the 30\% quoted for the United Kingdom (5). In the United Kingdom, there are 261,000 episodes of CAP each year, of which 83,153 (31.8\%) are admitted to hospital (5).

It is noteworthy that another study carried out in Spain using the national surveillance system for hospital data (7) indicated that the rate of hospitalization for pneumonia was $1.6 / 1000$ persons/year. Thus, it is likely that the rate of pneumonia is low in Spain. A study that more closely resembles the current study is that from Marston et al (8) who studied all adults residing in two counties in Ohio who were hospitalized in 1991 for the treatment of CAP. The overall rate of hospitalization was 260/100,000/year. The incidence was higher among blacks at 337/100,000/year than among whites at 253/100,000/year. Also, the incidence among men was higher than among women, 291/100,000/year versus 244/100,000/year, respectively (8). Because the study by Marston et al included only patients who had chest radiograph-confirmed CAP (our definite pneumonia), our rates of 220/100,000 and 180/100,000 for definite pneumonia requiring admission to hospital for year 1 and year 2 of the study are very similar.

Some striking findings from our study were the high rate of admission to an ICU for young persons who were admitted to hospital with pneumonia and the progressive decline in the admission rate to intensive care for those 65 years of age and older. In the Pneumonia Patient Outcomes Research Team (PORT) study (9) carried out in Boston, Pittsburgh and Halifax,

\section{REFERENCES}

1. Foy HM, Cooney MK, Allan I, Kenny GE. Rates of pneumonia during influenza epidemics in Seattle, 1964 to 1975. JAMA 1979;241:253-8.

2. Jokinen C, Heiskanen L, Juvonen $\mathrm{H}$, et al. Incidence of communityacquired pneumonia in the population of four municipalities in eastern Finland. Am J Epidemiol 1993;137:977-88.

3. Saynajakangas P, Keistinen T, Honkanen PO, Kivela SL. Hospitalization for pneumonia in the Finnish working-age population. Cent Eur J Public Health 1997;5:27-9.

4. Almirall J, Bolibar I, Vidal J, et al. Epidemiology of communityacquired pneumonia in adults: A population based study. Eur Respir J 2000;15:757-63.

5. Guest JF, Morris A. Community-acquired pneumonia: The annual cost to the National Health Service in the UK. Eur Respir J 1997;10:1530-4.

6. Basi SK, Marrie TJ, Huang JQ, Majumdar SR. Patients admitted to hospital with suspected pneumonia and normal chest radiographs: Epidemiology, microbiology and outcomes. Am J Med 2004;117:305-11.

7. Monge V, San-Martin M, Gonzalez A. The burden of community-acquired pneumonia in Spain. Eur J Public Health 2001;11:362-4.

8. Marston BJ, Plouffe JF, File TM Jr, et al. Incidence of communityacquired pneumonia requiring hospitalization. Results of active
$170(12.7 \%)$ of the patients were admitted to an ICU for treatment of CAP (9); however, this was not a population-based study. Moine et al (10) indicated that $18 \%$ to $36 \%$ of patients who were admitted to hospital for the treatment of CAP required admission to an ICU. Kaplan et al (11) conducted a study of all Medicare recipients hospitalized for the treatment of pneumonia in the United States in 1997 and found that the percentage of patients 65 years of age and older admitted to an ICU was $22.4 \%$. The percentage of patients in our study who were 65 years of age and older and who were admitted to ICU was $7.6 \%$.

The seasonal effect on pneumonia admissions has been known for some time. In Finland, the peak months for the admission of patients to hospital with pneumonia were December and January and the months with the lowest admissions were July and August (12). Often, this seasonal increase coincides with influenza activity in the community (13). It is noteworthy that influenza activity was minimal in Edmonton during the two years of the present study.

A strength of our study was the enrollment of all patients who presented to an emergency department with pneumonia in a large city over two years. A weakness was that we did not study patients who were seen in physicians' offices and were diagnosed with pneumonia; however, it is almost impossible to do this in such a large population. For this reason, enrolling all patients who present to an emergency department in a city with pneumonia is an attractive method for performing a population-based study. If such a method was embraced by other centres, we could readily compare the epidemiology of pneumonia.

\section{CONCLUSIONS}

The pneumonia admission rates were remarkably stable over the two years of the study. As expected, the percentage of patients who were admitted increased with increasing age. The effect of age on admission to ICU was striking and unexpected, and requires further study. The effect of climate on the number of patients with pneumonia presenting to an emergency department was considerable, with a major increase observed during the winter months.

population based surveillance study in Ohio. The CommunityBased Pneumonia Incidence Study Group. Arch Intern Med 1997;157:1709-18.

9. Angus D, Marrie TJ, Obrosky DS, et al. Severe communityacquired pneumonia: Use of intensive care services and evaluation of American and British Thoracic Society Diagnostic criteria. Am J Respir Crit Care Med 2002;166:717-23.

10. Moine P, Vercken JB, Chevret S, Gajdos P. Severe communityacquired pneumococcal pneumonia. The French Study Group of Community-Acquired Pneumonia in ICU. Scand J Infect Dis 1995;27:201-6.

11. Kaplan V, Angus DC, Griffin MF, Clermont G, Scott Watson R, Linde-Zwirble WT. Hospitalized community-acquired pneumonia in the elderly: Age- and sex-related patterns of care and outcomes in the United States. Am J Respir Crit Care Med 2002;165:766-72.

12. Sayanjakangas P, Keistinen T, Tuuponen T. Seasonal fluctuations in hospitalisation for pneumonia in Finland. Int J Circumpolar Health 2001;60:34-40.

13. Upshur RE, Goel V. Measuring the impact of influenza on the hospital admission rates of the elderly in Ontario: A five-year admission rate analysis, 1988-1993. Can J Public Health 2000;91:144-7. 


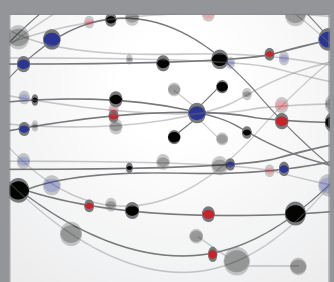

The Scientific World Journal
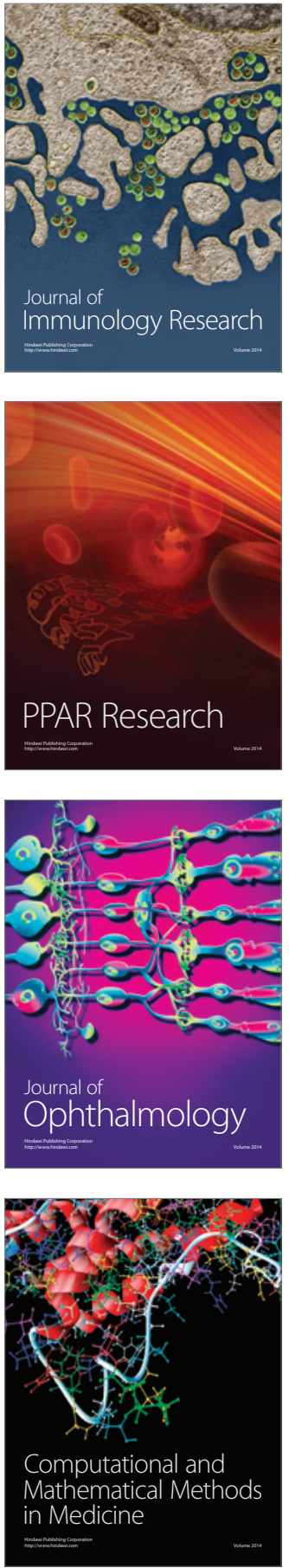

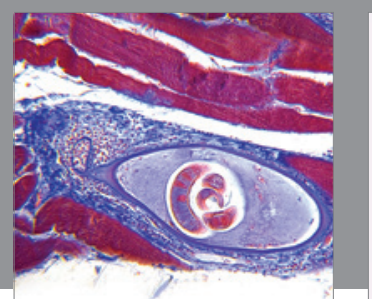

Gastroenterology Research and Practice

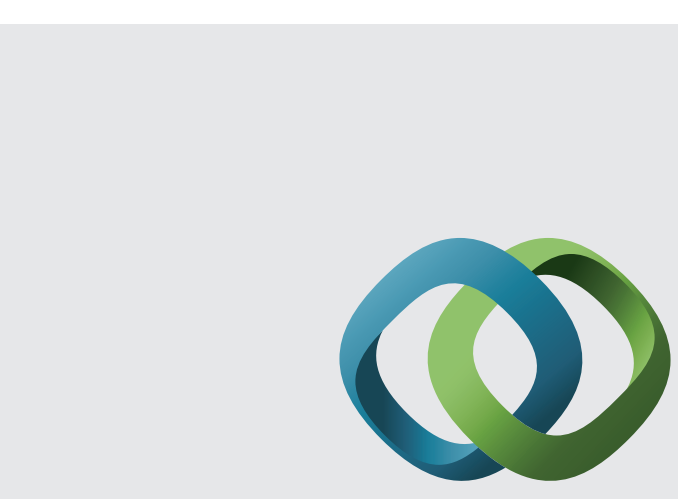

\section{Hindawi}

Submit your manuscripts at

http://www.hindawi.com
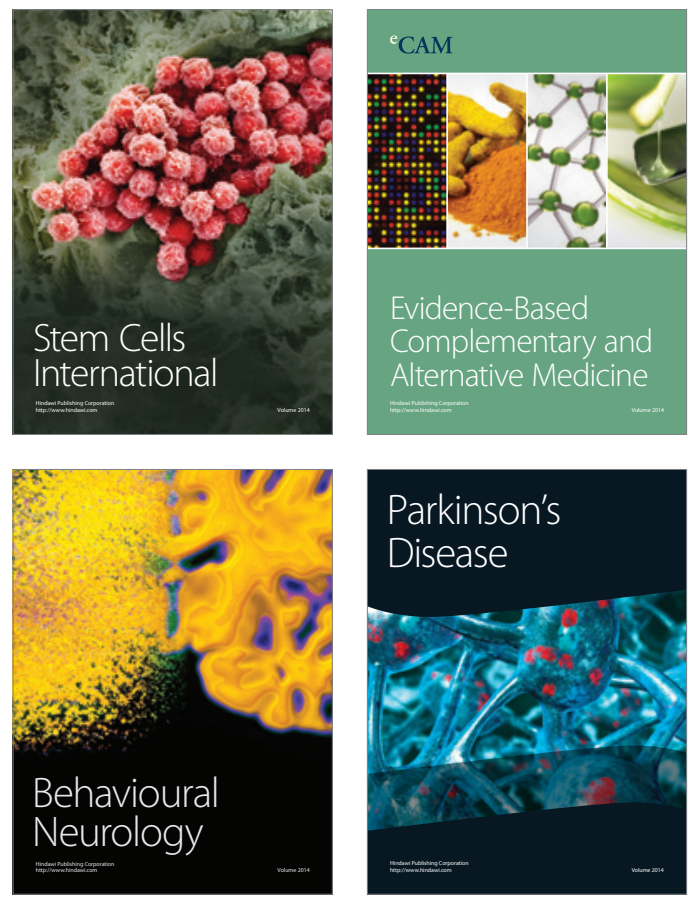
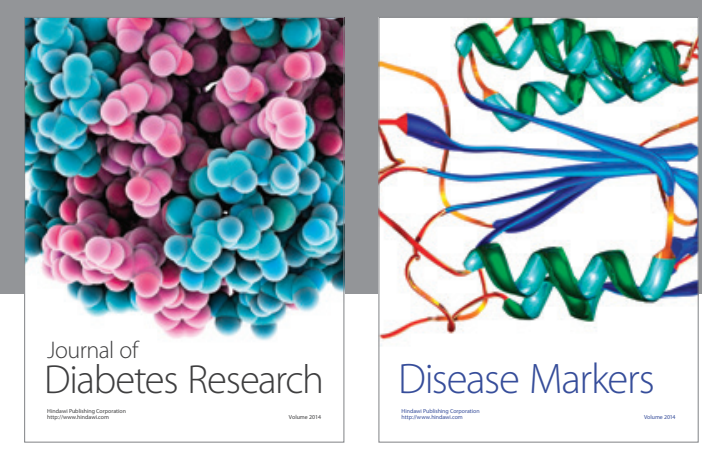

Disease Markers
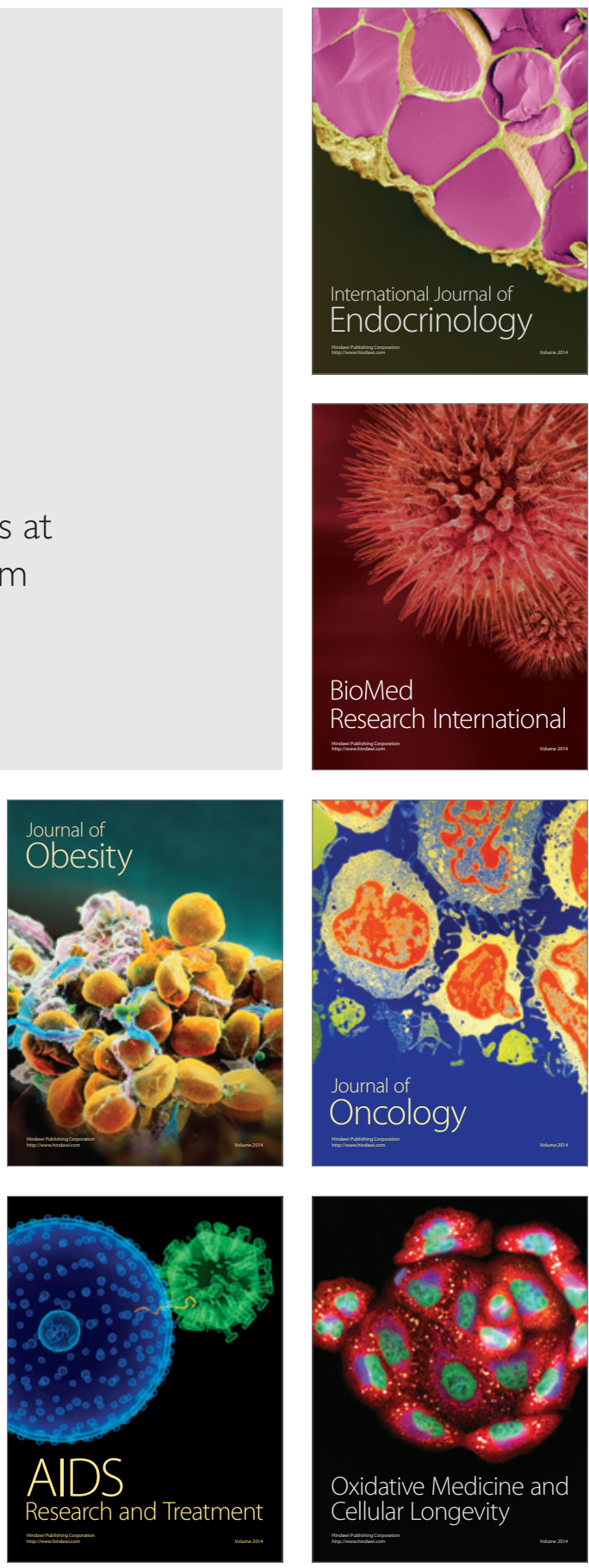